\title{
Non-Medical Errors: Time to Act
}

\author{
Kundan Mittal ${ }^{1}$, Anurag Aggarwal ${ }^{2}$ \\ ${ }^{1}$ Professor in Paediatrics, Intensive care/Respiratory Medicine, PGIMS, Rohtak-124001, India \\ ${ }^{2}$ Additional Director, NBE, Ansari Nagar New Delhi-29, India \\ Corresponding Author: Kundan Mittal
}

\begin{abstract}
Inadequate medical facilities are not the important cause of morbidity and mortality. In present era most of deaths are preventable if timely intervention is done. Poor referral transport, attitude, inadequate skills, and poor response time are some of important cause of preventable mortality. Time has come to react on these issues and think beyond.
\end{abstract}

Keywords: Non-medical error, transport, intern

We are in a habit to blame that facilities are not adequate or available in the hospital setting at many level and deaths are not avoidable. Do we feel that this is the truth? Most of the deaths in the hospital settings are preventable (depending on type of problems or etiology). Children including newborns have better outcome if timely help or intervention is provided to sick one. Parents bring their child to health care facility with the hope that Doctor is God and can save their hope and it is true to some extent. We also understand that treatment is matter of faith and doctors are most trust worthy people in the eyes of Parents, Patients, Family or Society. We became or become doctor to serve humanity but forget our primary responsibility and run after other various things. We perform our duty to save our self rather than patient/child's life, so that we are not blamed by any person or law. In a professional college or teaching institute doctors and other health care providers have more responsibilities towards Society and Nation but how much we are justifying our position can be assessed from hospital statistics. If a child dies in the hospital we usually blame the family for not reporting to health care facility at appropriate time, disease was of serious nature and not treatable, inadequate facilities, poverty, and/or Government is not providing adequate facility to health care providers in term of pay, material and equipment's. In our opinion these are not major factors contributing to childhood mortality but much importance has been given to these issues. In various peripheral health care centers health providers are either not present (may be busy in administrative or other work) or not performing sincerely. Many administrative work done at peripheral centers by doctors may be taken care by management professionals (MBA's) and services of health care providers can be utilized properly. We have set goals to decrease mortality and not the morbidity, a major concern in present situation. Time has come to think about morbidity assessment too so that burden the society and country can be brought down. Morbidity or disability will result lot of social, economic, and growth concern on the country.

Most of the time parents or family are not aware of appropriate health care facility and information available to society and family is also not adequate (place and person).If a well-developed communication system (contact person) during emergency and basic care provided at door step can save many lives. Transportation of sick child or newborn without stabilization from primary or secondary site (including intra-hospital transport) is an issue and no one is concerned. This also leads to increased morbidity and mortality. Time has come to have pre hospital life support care provider or emergency medical technician. Concept of transport team in India is poor. There is an urgent need to focus on this issue. Timely referral from outside and intrahospital referral (within department or in between departments) also emerging one of factors for morbid status of child.

In the emergency situations when doctor/staff does not listen to parents or family having indifferent attitude, inadequately skilled, less confident, poorly trained and dedicated and understaffing can increase the problem of child and needs to be addressed. The facility provided to health care providers at rural center is also big issue for indifferent attitude and poor availability of staff. Poverty is big issue in India but government sector is trying best to overcome and not the sole factors contributing towards mortality (data does not support to this much).Negligence or ignorance of parents do contribute to child life but not a major issue (no data available in India).Unethical practices do contribute to child morbidity. Resources of the family is not a big concern in a few States of India. Preparations to accept the patient are not adequate in many hospitals in India. The person in-charge thinks he or she knows the best and can perform the best.

Other possible contributors of morbidity and mortality are: identification of sickness (triage), medical errors, negligence (deliberate or knowingly), medical subject skills and knowledge, communication and team work, poor staffing, delay in execution treatment orders from doctor and or by nurse, poor technique or skill of reassessment of patient or health program, less trained and dedicated nurses and other health care staff, attitude, no guidelines or protocol, dedicated team, hospital associated infections, review of mortality and lesson learnt from it are major factors and need immediate attention.

Time has come to implement and take necessary steps in all the above areas of concern. These are not vaccine preventable, communicable or related to community program issues. All these factors are human related and does not require huge amount of finance. A well trained doctor 


\section{International Journal of Science and Research (IJSR) \\ ISSN (Online): 2319-7064}

Index Copernicus Value (2013): 6.14 | Impact Factor (2014): 5.611

during internship period in these areas can be a big help. Thus internship training period should be utilized to focus these issues/areas and should be made mandatory to get medical degree. This will further help in reducing the burden of the Government in terms finance, resource, manpower and in final outcome.

\section{References}

[1] Kaldjian LC, Jones EW, Wu BJ, Forman-Hoffman VL, Levi BH, Rosenthal GE. Reporting medical errors to improve patient safety: a survey of physicians in teaching hospitals. Arch Intern Med. 2008;168(1):4046

[2] Kohn LT, ed, Corrigan JM, ed, Donaldson MS, ed. To Err Is Human: Building a Safer Health System. Washington, DC: National Academy Press; 2000

[3] Hayward RA, Hofer TP. Estimating hospital deaths due to medical errors. Journal of the American Medical Association 2001; 286:415-20

[4] National Research Council. Crossing the Quality Chasm: A new health system for the 21st Century. National Academies Press, 2001.

[5] James, JT A New, Evidence-based Estimate of Patient Harms Associated with Hospital Care. Journal of Patient Safety 2013; 9: 122-8 doi: 10.1097/PTS.0b013e3182948a69 